\title{
Erratum to: The Sacred in Exile
}

\section{Erratum to: \\ G. McCann and G. Bechsgaard, The Sacred in Exile, https://doi.org/10.1007/978-3-319-66499-6}

The original version of the book was inadvertently published prematurely before incorporating the final corrections due to an error in the production process. The version supplied here has been corrected and approved by the author. 